\title{
Thymidylate synthase and thymidine phosphorylase mRNA expression in primary lesions using laser capture microdissection is useful for prediction of the efficacy of FOLFOX treatment in colorectal cancer patients with liver metastasis
}

\author{
KENSUKE KUMAMOTO, KOKI KUWABARA, YUSUKE TAJIMA, KUNIHIKO AMANO, SATOSHI HATANO, \\ TOMONORI OHSAWA, NORIMICHI OKADA, KEIICHIRO ISHIBASHI, NORIHIRO HAGA and HIDEYUKI ISHIDA
}

Department of Digestive Tract and General Surgery, Saitama Medical Center,

Saitama Medical University, Saitama 350-8550, Japan

Received October 6, 2011; Accepted January 17, 2012

DOI: $10.3892 / \mathrm{ol} .2012 .598$

\begin{abstract}
Chemotherapy with FOLFOX, which is a combination of 5-fluorouracil (5-FU)/leucovorin (LV) and oxaliplatin, has been used worldwide for the treatment of metastatic colorectal cancer patients. The aim of this study was to examine the candidates for predictors of the efficacy of the FOLFOX treatment regimen in colorectal cancer patients with liver metastasis, using formalin-fixed paraffin-embedded specimens. We investigated the mRNA levels of thymidylate synthase (TS), thymidine phosphorylase (TP), dihydropyrimidine dehydrogenase (DPD), orotate phosphoribosyltransferase (OPRT) and excision repair cross-complementing 1 (ERCC1) in 70 primary lesions and 30 liver metastatic lesions of colorectal cancer patients, using laser capture microdissection and real-time PCR methods. We then analyzed the correlation between their expression in primary lesions and those in corresponding liver metastatic lesions $(n=30)$ and the relationship between their expression in the primary lesions and the efficacy of mFOLFOX6 in 45 colorectal cancer patients with unresectable liver metastasis. The gene expression in primary lesions positively correlated with those in corresponding liver metastatic lesions. The profiles of gene expression of primary lesions strongly correlated with those of synchronous liver metastatic lesions compared to that of metachronous liver metastatic lesions. TS and TP mRNA levels in the patients with complete response, partial response or stable disease $(n=34)$ were significantly lower compared to those in the patients with progressive disease $(n=11)(p=0.017$ and $p=0.04$,
\end{abstract}

Correspondence to: Dr Kensuke Kumamoto, Department of Digestive Tract and General Surgery, Saitama Medical Center, Saitama Medical University, Saitama 350-8550, Japan

E-mail:kumamotk@saitama-med.ac.jp

Key words: FOLFOX, colorectal cancer, thymidylate synthase, thymidine phosphorylase, excision repair cross-complementing 1 , laser capture microdissection respectively). Our results indicated that TS and TP mRNA expression profiles in primary lesions are sufficient to estimate the mRNA expression profiles in synchronous liver metastatic lesions compared to metachronous liver metastatic lesions. Additionally, these profiles may be useful predictors in the identification of eligible colorectal cancer patients with liver metastasis for FOLFOX treatment.

\section{Introduction}

Advances in chemotherapy for metastatic colorectal cancer have lead to improvements in overall survival $(1,2)$. As the worldwide guidelines for colorectal cancer treatment have recommended, FOLFOX, which consists of a combination of 5-fluorouracil (5-FU)/leucovorin (LV) and oxaliplatin, is one of the first-line standard chemotherapies for metastatic colorectal cancer, as well as FOLFIRI, consisting of 5-FU/ $\mathrm{LV}$ and irinotecan. A number of reports showed that the response rate to FOLFOX is approximately $20-50 \%(1,3-5)$. These increases in the response rate have markedly improved the overall survival in metastatic colorectal cancer patients. However, the remaining patients do not benefit from the FOLFOX treatment. The patients who receive chemotherapy usually suffer from adverse events including myelosuppression, nausea, diarrhea and peripheral paresthesia (1-3). Numerous patients undergoing FOLFOX treatment have complained of peripheral neuropathy induced by oxaliplatin. If the efficacy of FOLFOX treatment were favorable, the benefits of treatment are likely to be greater than the disadvantages of the adverse events caused by the anti-cancer drugs. However, if we were able to recognize unfavorable outcomes in advance when patients with metastatic colorectal cancer receive FOLFOX treatment, we would avoid ineffective treatment and go directly to more efficacioius chemotherapeutic drugs. To perform chemotherapy more effectively, predictive markers of chemosensitivity are required.

Candidates for predictive markers of the efficacy of chemotherapy on various types of cancer have been investigated. Regarding colorectal cancer treatment, genes related 
to the drug metabolism pathway of 5-FU were previously studied intensively (6-10). Thymidylate synthase (TS), thymidine phosphorylase (TP), dihydropyrimidine dehydrogenase (DPD) and orotate phosphoribosyltransferase (OPRT) are key enzymes involved in DNA and RNA synthesis (11). Of these, TS expression appears to be a more useful indicator for the prediction of chemosensitivity and prognosis. Previous reports indicated that colorectal cancer patients with low levels of TS expression had better prognosis than those with high levels of TS expression (6,8-10). By contrast, patients with a high level of TS expression who underwent curative resection of colorectal cancer had more effective resection when the patients received 5-FU-based treatment as adjuvant chemotherapy $(12,13)$. TP is identical to platelet-derived endothelial cell growth factor (PD-ECGF) and is crucial in angiogenesis in various types of cancer (14). The clinical significance of a high TP expression is associated with resistance to 5-FU-based chemotherapy and poor prognosis in colorectal cancer $(7,14)$. Excision repair cross-complementing 1 (ERCC1) is involved in the repair of damaged DNA (15). ERCC1 expression is reportedly correlated with resistance to platinum-based drugs, including oxaliplatin $(9,10)$.

When we predict the efficacy of chemotherapy for metastatic lesions, two methods may be used: one prediction method is to estimate using the expression profiles of primary lesions and the other method involves investigating metastatic lesions directly. There appears to be no consensus on which method is better in the identificaiton of predictive markers of chemosensitivity. Although a previous report (16) demonstrated that TS mRNA expression differed depending on the organs in which metastatic lesions developed, there is a possibility that even if metastatic lesions developed in the same organ, the mRNA expression profiles may be different due to the development pattern of metastasis: synchronous or metachronous metastasis. Previous reports (17-19) have shown the relationship of mRNA expression between the primary lesions and corresponding liver metastatic lesions in colorectal cancer. However, obtaining specimens from metastatic tumors appears to be difficult in clinical practice. Ideally, the efficacy of chemotherapy for metastatic lesions is predicted by examining gene expression in the resected primary lesions.

In the present study, we investigated the correlation of TS, TP, DPD, OPRT and ERCC1 mRNA expression in a primary lesion, and the comparison between the expression of primary lesions and those of corresponding synchronous or metachronous liver metastatic lesions using laser capture microdissection and real-time PCR methods. Moreover, we analyzed the relationship between the response of FOLFOX treatment and the levels of TS, TP, DPD, OPRT and ERCC1 mRNA expression.

\section{Materials and methods}

Clinical samples of patients. Formalin-fixed paraffinembedded (FFPE) specimens obtained from 70 patients (24 females and 46 males) with primary colorectal cancer who underwent surgery at our institute between 2005 and 2009 were used to investigate the correlation of TS, TP, DPD, OPRT and ERCC1 mRNA expression in primary colorectal cancer. The median age of the patients was 65 years (range,
32-85). The carcinomas at the time of primary tumor resection were staged according to the UICC classification. These cases included stage I, 2 cases; stage II, 17 cases; stage III, 9 cases; and stage IV, 42 cases.

Of the 70 patients, 30 patients with liver metastasis, which included 15 synchronous and 15 metachronous liver metastases, underwent biopsy or potentially curative resection of liver metastatic tumors. Of 15 patients with metachronous liver metastasis, 10 patients received adjuvant chemotherapy with oral 5-FU drugs for 6 months following the resection of primary lesions. Previous adjuvant chemotherapy was completed at least 6 months prior to inclusion. FFPE specimens of liver metastatic tumors in these 30 patients were examined for the expression profiles of TS, TP, DPD, OPRT and ERCC1 mRNA. We analyzed the alteration of these mRNA levels and the correlation of the expression of these enzymes in primary lesions and liver metastatic lesions.

Of the 70 patients, 45 patients with unresectable liver metastasis (39 synchronous and 6 metachronous metastasis) who received mFOLFOX6 (5) as the first-line chemotherapy were used to investigate the relationship between the mRNA level of each enzyme and the efficacy of mFOLFOX6 treatment. The response to mFOLFOX6 treatment was evaluated during 4 to 6 courses of the treatment according to the Response Evaluation Criteria in Solid Tumors (RECIST version 1.1). We defined complete response (CR), partial response (PR) and stable disease (SD) as a responder group, and progressive disease (PD) as a non-responder group. The response was observed as follows: $\mathrm{CR}$ in one patient, $\mathrm{PR}$ in 20 patients, SD in 13 patients, and PD in 11 patients.

This study was performed in accordance with the ethics guidelines for clinical research with the approval of our institutional ethics committee. Informed consent was obtained from the individuals included in the study.

Laser capture microdissection and RNA extraction. A representative FFPE tumor specimen was selected by a pathologist following examination of the hematoxylin and eosin-stained slides. Sections $(10-\mu \mathrm{m})$ were stained with neutral fast red to enable visualization of histology for laser capture microdissection (P.A.L.M. Microlaser Technologies AG, Munich, Germany), which was performed to ensure that only tumor cells were studied. RNA was isolated from FFPE specimens using a novel, proprietary procedure (Response Genetics, Los Angeles, CA, USA). Following RNA isolation, cDNA was obtained from each sample according to a previously described procedure (20).

PCR quantification of $m R N A$ expression. Target cDNA sequences were amplified by quantitative PCR using a fluorescence-based real-time detection method (ABI PRISM 7900, Applied Biosystems, Foster City, CA, USA). The $25 \mu \mathrm{l}$ $\mathrm{PCR}$ reaction mixture contained $600 \mathrm{nmol} / \mathrm{l}$ of each primer, $200 \mathrm{nmol} / \mathrm{l}$ each of dATP, dCTP and dGTP, $400 \mu \mathrm{mol} / \mathrm{l} \mathrm{dUTP}$, $5.5 \mathrm{mmol} / 1 \mathrm{MgCl}_{2}$, and $1 \mathrm{X}$ TaqMan buffer containing a reference dye (all reagents were supplied by Applied Biosystems). The PCR conditions were $50^{\circ} \mathrm{C}$ for $10 \mathrm{sec}$ and $95^{\circ} \mathrm{C}$ for $10 \mathrm{~min}$, followed by 42 cycles at $95^{\circ} \mathrm{C}$ for $15 \mathrm{sec}$ and $60^{\circ} \mathrm{C}$ for $1 \mathrm{~min}$. The information on the primer sequence and probes used for TS, TP, DPD, OPRT and ERCC1 were described in previous 
reports $(17,18)$. The level of expression for each mRNA is the ratio against the amounts of $\beta$-actin used as an internal control.

Statistical analysis. The Pearson product-moment correlation coefficient was used to determine the correlations between the expression of each of the studied mRNA molecules and other molecules in primary colorectal cancer, and to analyze the correlation of expression of each of the studied mRNA molecules between primary colorectal cancer and corresponding liver metastatic cancer. To compare the mRNA level of each molecule between the responder group and the non-responder group, the Wilcoxon signed-rank test was used. The paired t-test was used to investigate the alteration of the mRNA level of each molecule in the primary tumor with that in the liver metastatic tumor. The level of mRNA expression was expressed as the mean \pm standard deviation. A statistically significant difference was noted at $\mathrm{P}<0.05$. Statistical analysis was performed with Prism 5 software (GraphPad Software, Inc., La Jolla, CA, USA).

\section{Results}

Correlation of TS, TP, DPD, OPRT and ERCC1 mRNA expression in 70 primary lesions of colorectal cancer patients. TS mRNA expression positively correlated with OPRT and ERCC1 mRNA expression but the tendency was weak $(r=0.43$, $\mathrm{p}=0.0002 ; \mathrm{r}=0.31, \mathrm{p}=0.009$, respectively) (Fig. 1). There was a marked and positive correlation between TP and DPD mRNA expression $(\mathrm{r}=0.82 ; \mathrm{p}<0.0001)$ and a weak correlation between TP and ERCC1 mRNA expression ( $r=0.25$; $\mathrm{p}=0.04$ ) (Fig. 1). ERCC1 mRNA expression was correlated weakly with OPRT mRNA expression $(\mathrm{r}=0.49 ; \mathrm{p}<0.0001)$ (Fig. 1). No other significant correlations were observed.

Alteration of TS, TP, DPD, OPRT and ERCC1 mRNA expression in primary lesions and liver metastatic lesions. A comparison between the levels of TS, TP, DPD, OPRT and ERCC1 mRNA expression in primary lesions $(n=30)$ and that in synchronous $(n=15)$ or metachronous $(n=15)$ liver metastatic lesions was performed. Results showed that OPRT and ERCC1 mRNA expression was significantly decreased in synchronous liver metastatic lesions as compared to primary lesions $(\mathrm{p}=0.036$ and $\mathrm{p}=0.044$, respectively) (Table I). No other significant differences were found in primary and liver metastatic lesions.

Correlation of TS, TP, DPD, OPRT and ERCC1 mRNA expression in primary lesions and corresponding synchronous and metachronous liver metastatic lesions. The expression of all of the genes in primary colorectal cancer lesions positively correlated with those in corresponding liver metastatic lesions (Fig. 2). Marked correlations were found between TP and DPD mRNA expression in primary lesions and that in liver metastatic lesions $(\mathrm{r}=0.8 ; \mathrm{p}<0.0001, \mathrm{r}=0.75$; $\mathrm{p}<0.0001$, respectively) (Fig. 2). Weak correlations between primary lesions and liver metastatic lesions were found in TS, DPD and ERCC1 mRNA expression ( $\mathrm{r}=0.57 ; \mathrm{p}<0.001$, $\mathrm{r}=0.52 ; \mathrm{p}=0.003, \mathrm{r}=0.68 ; \mathrm{p}<0.0001$, respectively) (Fig. 2). When the metastatic pattern was divided into synchronous metastasis and metachronous metastasis, there were marked correlations between primary lesions and synchronous liver
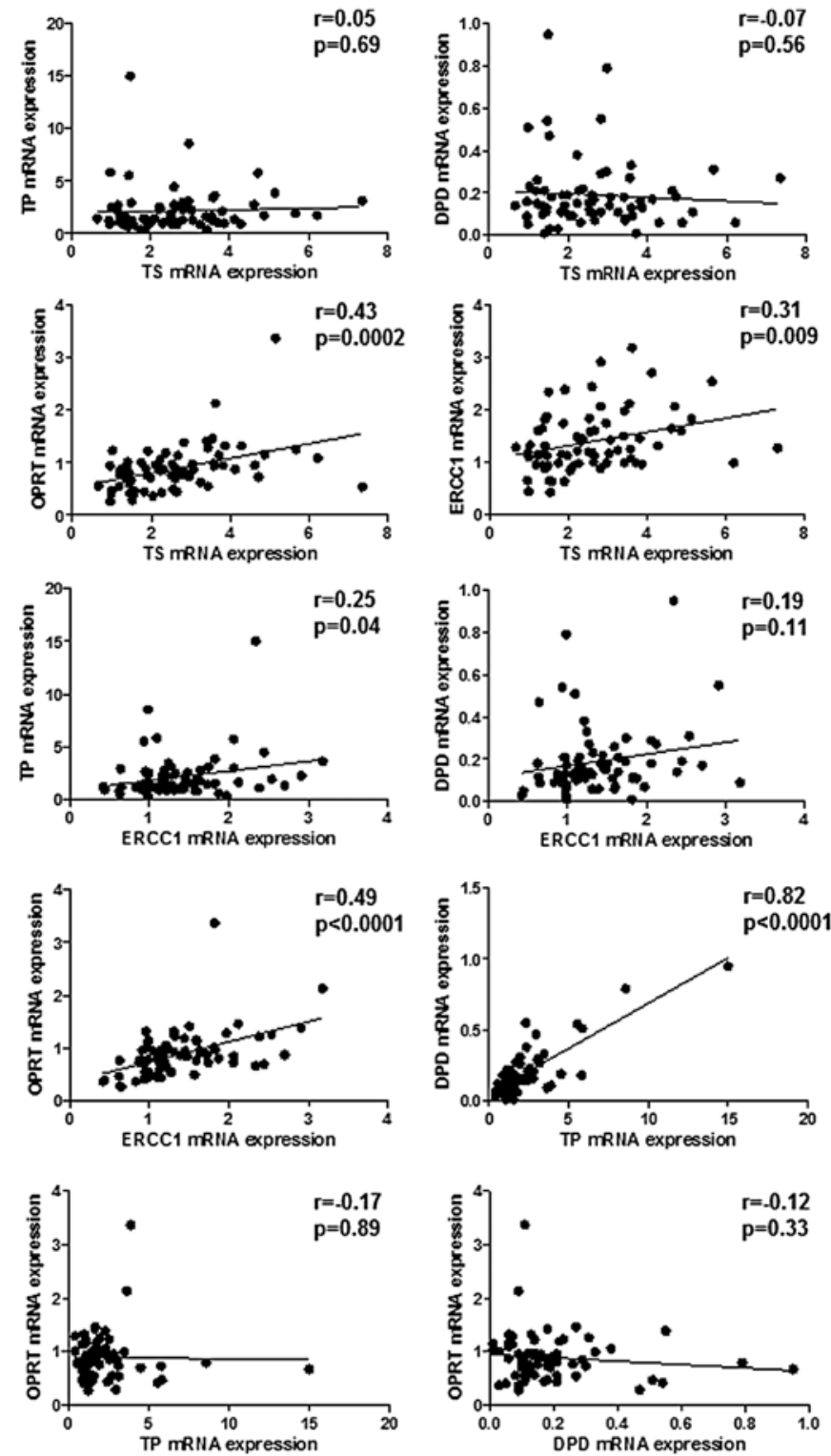

Figure 1. The correlation of TS, TP, DPD, OPRT and ERCC1 mRNA levels in 70 primary lesions of advanced colorectal cancer patients. The level of expression of each mRNA was expressed as the ratio to the amounts of $\beta$-actin mRNA expression. The indicated statistical analysis was performed by Pearson product-moment correlation coefficient.

metastatic lesions in TS, TP, DPD, OPRT and ERCC1 mRNA expression (Fig. 2). Regarding metachronous liver metastatic lesions, there were weak correlations between primary lesions and liver metastatic lesions in TS, TP and ERCC1 mRNA expression, while no correlations were observed in TP and DPD mRNA expression (Fig. 2).

The relationship between the response of FOLFOX and the level of TS, TP, DPD, OPRT and ERCC1 mRNA expression in primary colorectal cancers. The level of TS and TP $\mathrm{mRNA}$ in the responder group $(n=34)$ was significantly lower than that in the non-responder group $(n=11)(p=0.017$ and $p=0.04$, respectively) (Fig. 2). No significant differences were found between the level of DPD, OPRT and ERCC1 mRNA in the responder group and in the non-responder group (Fig. 3). 
Table I. The level of mRNA expression in primary colorectal cancer and liver metastatic cancer.

\begin{tabular}{|c|c|c|c|c|c|c|}
\hline & \multicolumn{3}{|c|}{ Synchronous liver metastasis $(\mathrm{n}=15)$} & \multicolumn{3}{|c|}{ Metachronous liver metastasis $(n=15)$} \\
\hline & Primary lesions & Liver metastatic lesions & P-value & Primary lesions & Liver metastatic lesions & P-value \\
\hline TS & $2.92 \pm 1.6$ & $2.47 \pm 1.32$ & 0.14 & $3.03 \pm 1.6$ & $3.4 \pm 2.2$ & 0.23 \\
\hline $\mathrm{TP}$ & $3.41 \pm 3.57$ & $3.61 \pm 4.72$ & 0.79 & $1.61 \pm 0.8$ & $2.05 \pm 1.41$ & 0.12 \\
\hline DPD & $0.23 \pm 0.24$ & $0.3 \pm 0.29$ & 0.16 & $0.19 \pm 0.12$ & $0.22 \pm 0.11$ & 0.15 \\
\hline OPRT & $1.14 \pm 0.78$ & $0.81 \pm 0.45$ & 0.036 & $0.92 \pm 0.28$ & $0.86 \pm 0.52$ & 0.34 \\
\hline ERCC1 & $1.72 \pm 0.7$ & $1.45 \pm 0.48$ & 0.044 & $1.5 \pm 0.62$ & $1.31 \pm 0.65$ & 0.19 \\
\hline
\end{tabular}

The mRNA expression was presented as the mean $\pm \mathrm{SD}$.

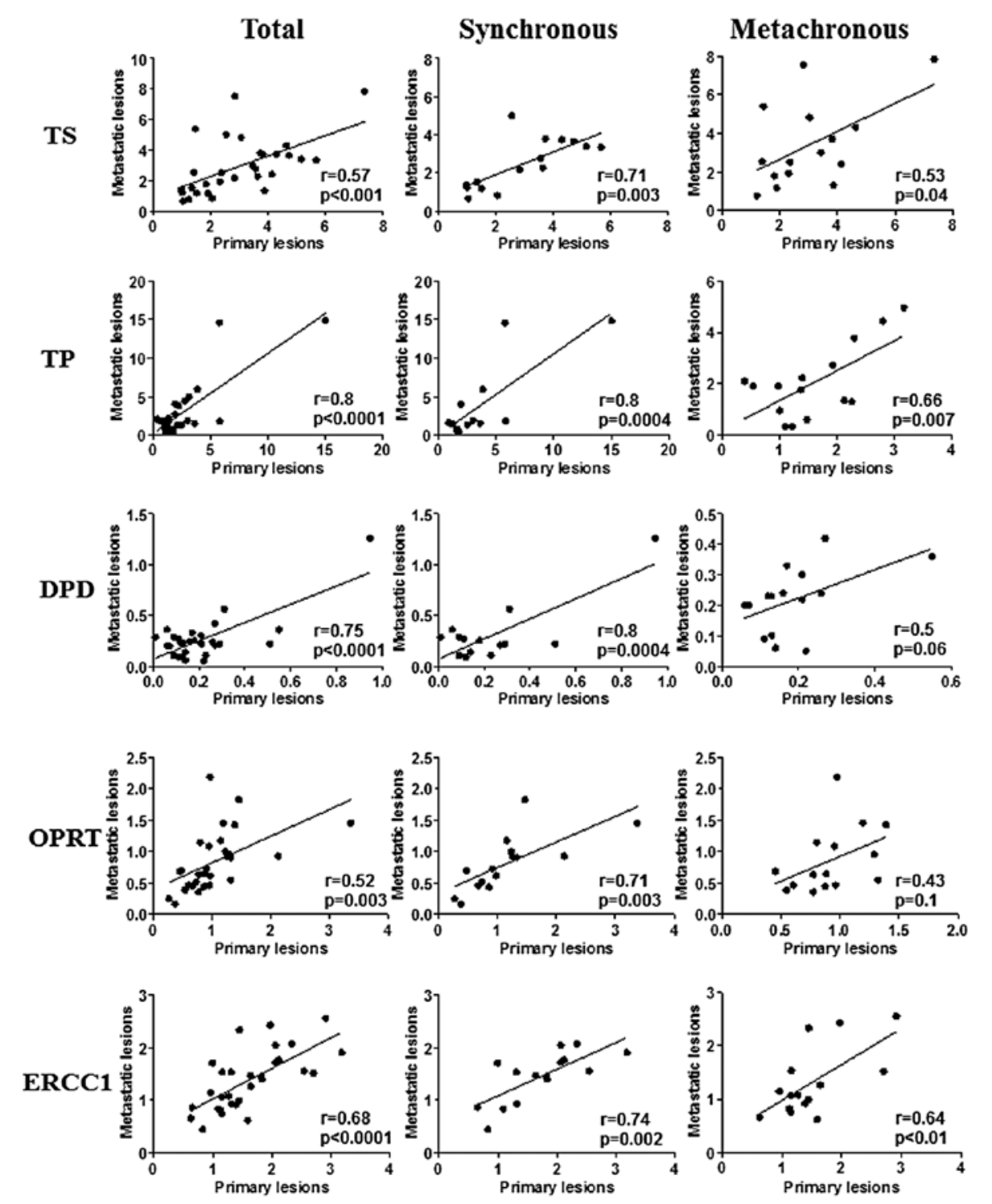

Figure 2. The correlation of TS, TP, DPD, OPRT and ERCC1 mRNA levels between primary lesions and corresponding liver metastatic lesions in 30 colorectal cancer patients with liver metastasis. The indicated statistical analysis was performed by Pearson product-moment correlation coefficient.

\section{Discussion}

Previously, 5-FU-based chemotherapy was performed for metastatic colorectal cancer patients and has also been administered to patients who underwent curative surgery for colorectal cancer as adjuvant chemotherapy (21). However, predictive markers for chemosensitivity to 5-FU and prognostic factors have been investigated to select eligible patients with colorectal cancer. Among genes that are correlated with the 5-FU metabolic pathway, TS, TP, DPD and OPRT 

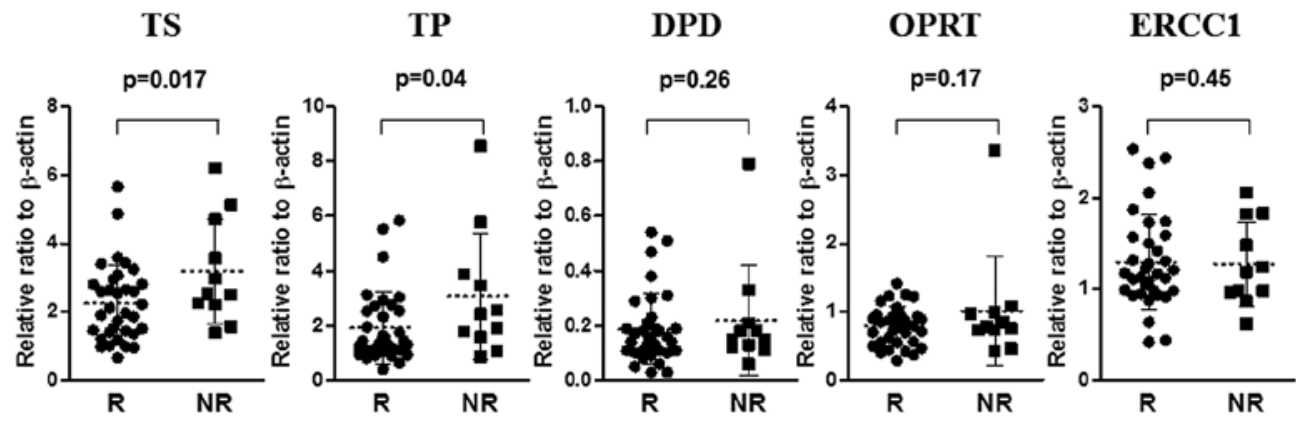

Figure 3. A comparison of TS, TP, DPD, OPRT and ERCC1 mRNA levels of 45 primary lesions in colorectal cancer patients with liver metastasis between the responder group $(R)(n=34)$ and the non-responder group $(N R)(n=11)$.

expression have been intensively assessed by real-time PCR, enzyme-linked immunosorbent assay (ELISA), and immunohistochemical methods. Thus, a number of investigators have reported the relationship between these expression profiles and clinical significance in predicting the efficacy of 5-FU treatment for metastatic colorectal cancer (6-10) and curatively resected colorectal cancer patients $(12,13)$. Recent standard chemotherapy for metastatic colorectal cancer has constituted multiple combinations of anti-cancer drugs with 5-FU. FOLFOX treatment has been recommended for metastatic colorectal cancer patients as the first- or second-line chemotherapy (1-4) and for stage III colon cancer patients as adjuvant chemotherapy (22). Oxaliplatin is classified as one of the platinum-based chemotherapeutic agents, along with cisplatin. However, its function is different from that of cisplatin as it has a 1,2-diaminocyclohexane carrier ligand in its chemical structure (23). Its cytotoxic effects are induced by the direct binding to interstrand DNA, interfering with DNA transcription and replication. ERCC1 is essentially involved in the recognition and removal of the platinum-DNA adducts (15). Thus, high levels of ERCC1 expression in cancer tissues attenuate the chemosensitivity of oxaliplatin $(24,25)$.

In the present study, we examined the mRNA expression of the 5-FU/oxaliplatin metabolism-related genes, including TS and ERCC1, in colorectal cancer patients with liver metastasis receiving FOLFOX treatment as first-line chemotherapy. Although there are only a few reports that have focused on the expression levels of those mRNAs to predict the efficacy of FOLFOX treatment, our results show that the levels of TS and TP mRNA expression in the responder group was significantly lower than that in the non-responder group, and was similar to previous reports $(9,10)$. Shirota et al demonstrated that low levels of TS and ERCC1 mRNA expression in liver metastatic tumors or recurrent colorectal tumor masses had favorable responses and prolonged survival compared with high levels of expression in colorectal cancer patients receiving a combination of 5-FU and oxaliplatin chemotherapy as the second- or third-line treatment using the laser capture microdissection method (9). Using immunohistochemistry, findings of another report have shown that a negative TS expression had a better response for 5-FU/oxaliplatin than a positive TS expression, while ERCC1 expression was not associated with the response to 5-FU/oxaliplatin chemotherapy as the first-line chemotherapy (10). Our study may be the first report to demonstrate the correlation between TS and TP mRNA expression of primary tumors and the efficacy of the first-line FOLFOX treatment in colorectal cancer with liver metastasis using the laser capture microdissection method. Prior to the era of FOLFOX treatment for metastatic colorectal cancer, patients with colorectal cancer receiving 5-FU treatment were surveyed to identify the predictive markers for chemotherapy outcome. Since then, TS and TP expression have been considered to be useful indicators to predict the efficacy of chemotherapy and prognosis in metastatic colorectal cancer patients (6-8). Our results suggest that even if 5-FU treatment changes to FOLFOX treatment, the evaluation of TS and TP mRNA expression in primary colorectal cancer tissues is likely to be useful in the prediction of the efficacy of FOLFOX treatment in colorectal cancer patients with liver metastasis, although it may be difficult to evaluate the efficacy of oxaliplatin by ERCC1 expression alone.

Regarding the comparison between the mRNA level of TS, TP, DPD, OPRT and ERCC1 expression in primary colorectal cancer lesions and that in synchronous or metachronous liver metastatic lesions, OPRT and ERCC1 mRNA levels were significantly decreased in synchronous liver metastatic lesions and no alteration of the TS and TP mRNA levels was observed. Although these investigations have previously been reported $(16-19,26,27)$, the results remain controversial. This discrepancy may be caused by the difference in methodology and study population. As for TS mRNA expression, almost all reports have demonstrated supportive results that there was not a significant alteration between primary tumor and liver metastatic tumor $(17,19,26,27)$, while it has been reported that the TS mRNA levels in metachronous liver metastases were higher than those in primary tumors (18). This evidence led us to the conclusion that examining the TS mRNA level in primary colorectal cancer tissue as a predictive indicator of chemosensitivity is sufficient and it is not necessary to know the TS mRNA level in liver metastatic cancer tissue.

We further demonstrated the significant correlation of TS, TP, DPD, OPRT and ERCC1 mRNA levels between primary colorectal cancer lesions and liver metastatic lesions. The correlation between synchronous liver metastatic lesions and primary lesions was stronger than that of metachronous liver metastatic lesions with regard to the mRNA level of the genes that we examined. This difference means the acquisition of tumor heterozygosity when the metachronous liver metastasis developed, and it may be caused by the effect of adjuvant chemotherapy with oral administration of 5-FU in the stage III 
colorectal cancer patients following curative resection of colorectal cancer. Previous studies (17-19) that analyzed the correlation of mRNA expression between primary colorectal cancer lesions and liver metastatic lesions have demonstrated similar results to our current results. In particular, the significant correlation of TS mRNA expression was consistent with our results. These experiments were performed by almost identical methods using FFPE samples. Another study (26) has shown that no correlations of TS, TP, DPD and OPRT mRNA expression were found in primary colorectal tumors and corresponding metastatic liver tumors using frozen tissues. In this case, the different results may be explained by the different materials used for RNA extraction. When FFPE samples are used through the laser capture microdissection method, the amount of mRNA expression reflects almost all cancer cells. However, it is likely that the frozen tissues include interstitial component cells with the exception of cancer cells. For this reason, the difference between component cells of primary colorectal cancer tissues and liver metastatic cancer tissues could affect these results. Therefore, when a comparison of mRNA expression among different organs is performed, the RNA extraction method through laser capture microdissection appears to be better since the mRNA expression of target genes reflects the product of cancer cells without interstitial component cells.

When the mRNA level of all molecules was compared among primary colorectal cancer tissues, there were significant correlations among TS, OPRT and ERCC1, and a strong correlation was observed between TP and DPD. The correlation between TS and OPRT mRNA levels has already been documented in a previous report (26). These enzymes may work in a coordinated manner as a critical step in the de novo pathway of DNA synthesis. Thus, the alteration of OPRT mRNA expression may be associated with that of TS mRNA expression. Regarding the correlation between TS and OPRT expression, the combination of OPRT with a high expression and TS with a low expression is considered to be effective for chemotherapy (28). Moreover, a weak correlation was found between TS and ERCC1 mRNA expression. These results suggest that the measurement of only TS mRNA expression is adequate to predict the efficacy of chemotherapy without the measurement of OPRT and ERCC1 mRNA expression. The strong correlation between TP and DPD has been described in numerous previous reports $(17,19,26,29-32)$. This consistent result indicated that this correlation is adequate to examine either TP or DPD mRNA expression. In terms of clinical significance, the lower expression of TP and DPD had a better response to 5-FU treatment for colorectal cancer patients (8).

Progress in systemic chemotherapy, including moleculartargeted therapy for metastatic colorectal cancer, enables conversion therapy. As such, unresectable metastatic tumors become resectable (33). A strong correlation has been reported between response rates and the liver resection rate in patients with isolated liver metastases (34). The addition of bevacizumab (35) to the FOLFOX and FOLFIRI regimens, or the addition of cetuximab (36) in cases with wild-type KRAS expression, has been suggested to be effective. Oncologists tend to spend their efforts on how to use monoclonal antibodies to increase the response rate for metastatic colorectal cancer. However, when we consider the root of chemotherapy, it remains important to predict the efficacy of FOLFOX, which is a basic regimen of multi-drug combination therapy. Furthermore, the present results showing that the mRNA expression profiles in primary colorectal cancer lesions correlated strongly with those in synchronous liver metastatic lesions would be useful to predict the efficacy of FOLFOX for metastatic lesions. As a result, an increase in the probability of actual conversion therapy is likely to occur.

Taken together, our current results indicate that the measurement of the TS and TP mRNA levels may estimate the ERCC1, OPRT and DPD mRNA levels in primary colorectal cancer and may be useful in the prediction of the efficacy of FOLFOX treatment in liver metastatic lesions, particularly synchronous liver metastatic lesions, reflecting the mRNA expression profiles of all molecules in primary colorectal cancer tumor. This evidence may contribute to the clinical application for future strategies, including conversion therapy.

\section{References}

1. de Gramont A, Figer A, Seymour M, Homerin M, Hmissi A, Cassidy J, Boni C, Cortes-Funes H, Cervantes A, Freyer G, Papamichael D, Le Bail N, Louvet C, Hendler D, de Braud F, Wilson C, Morvan F and Bonetti A: Leucovorin and fluorouracil with or without oxaliplatin as first-line treatment in advanced colorectal cancer. J Clin Oncol 18: 2938-2947, 2000.

2. Tournigand C, André T, Achille E, Lledo G, Flesh M, Mery-Mignard D, Quinaux E, Couteau C, Buyse M, Ganem G, Landi B, Colin P, Louvet C and de Gramont A: FOLFIRI followed by FOLFOX6 or the reverse sequence in advanced colorectal cancer: a randomized GERCOR study. J Clin Oncol 22: 229-237, 2004.

3. Goldberg RM, Sargent DJ, Morton RF, Fuchs CS, Ramanathan RK, Williamson SK, Findlay BP, Pitot HC and Alberts SR: A randomized controlled trial of fluorouracil plus leucovorin, irinotecan, and oxaliplatin combinations in patients with previously untreated metastatic colorectal cancer. J Clin Oncol 22: 23-30, 2004.

4. Reddy GK, Gibson AD and Price N: Evolution of FOLFOX regimens in the treatment of advanced colorectal cancer. Clin Colorectal Cancer 4: 296-299, 2005.

5. Shimizu T, Satoh T, Tamura K, Ozaki T, Okamoto I, Fukuoka M and Nakagawa K: Oxaliplatin/fluorouracil/leucovorin (FOLFOX4 and modified FOLFOX6) in patients with refractory or advanced colorectal cancer: post-approval Japanese population experience. Int J Clin Oncol 12: 218-223, 2007.

6. Leichman CG, Lenz HJ, Leichman L, Danenberg K, Baranda J, Groshen S, Boswell W, Metzger R, Tan M and Danenberg PV: Quantitation of intratumoral thymidylate synthase expression predicts for disseminated colorectal cancer response and resistance to protracted-infusion fluorouracil and weekly leucovorin. J Clin Oncol 15: 3223-3229, 1997.

7. Metzger R, Danenberg K, Leichman CG, Salonga D, SchwartzEL, Wadler S, Lenz HJ, Groshen S, Leichman L and Danenberg PV: High basal level gene expression of thymidine phosphorylase (platelet-derived endothelial cell growth factor) in colorectal tumors is associated with nonresponse to 5-fluorouracil. Clin Cancer Res 4: 2371-2376, 1998.

8. Salonga D, Danenberg KD, Johnson M, Metzger R, Groshen S, Tsao-Wei DD, Lenz HJ, Leichman CG, Leichman L, Diasio RB and Danenberg PV: Colorectal tumors responding to 5-fluorouracil have low gene expression levels of dihydropyrimidine dehydrogenase, thymidylate synthase, and thymidine phosphorylase. Clin Cancer Res 6: 1322-1327, 2000.

9. Shirota Y, Stoehlmacher J, Brabender J, Xiong YP, Uetake H, Danenberg KD, Groshen S, Tsao-Wei DD, Danenberg PV and Lenz HJ: ERCC1 and thymidylate synthase mRNA levels predict survival for colorectal cancer patients receiving combination oxaliplatin and fluorouracil chemotherapy. J Clin Oncol 19: 4298-4304, 2001

10. Kim SH, Kwon HC, Oh SY, Lee DM, Lee S, Lee JH, Roh MS, Kim DC, Park KJ, Choi HJ and Kim HJ: Prognostic value of ERCC1, thymidylate synthase, and glutathione S-transferase pi for 5-FU/oxaliplatin chemotherapy in advanced colorectal cancer. Am J Clin Oncol 32: 38-43, 2009. 
11. Koopman M, Venderbosch S, Nagtegaal ID, van Krieken JH and Punt CJ: A review on the use of molecular markers of cytotoxic therapy for colorectal cancer, what have we learned? Eur J Cancer 45: 1935-1949, 2009.

12. Edler D, Glimelius B, Hallström M, Jakobsen A, Johnston PG, Magnusson I, Ragnhammar P and Blomgren H: Thymidylate synthase expression in colorectal cancer: a prognostic and predictive marker of benefit from adjuvant fluorouracil-based chemotherapy. J Clin Oncol 20: 1721-1728, 2002.

13. Kornmann M, Schwabe W, Sander S, Kron M, Sträter J, Polat S, Kettner E, Weiser HF, Baumann W, Schramm H, Häusler P, Ott K, Behnke D, Staib L, Beger HG and Link KH: Thymidylate synthase and dihydropyrimidine dehydrogenase mRNA expression levels: predictors for survival in colorectal cancer patients receiving adjuvant 5-fluorouracil. Clin Cancer Res 9: 4116-4124, 2003.

14. Takebayashi Y, Akiyama S, Akiba S, Yamada K, Miyadera K, Sumizawa T, Yamada Y,Murata F and Aikou T: Clinicopathologic and prognostic significance of an angiogenic factor, thymidine phosphorylase, in human colorectal carcinoma. J Natl Cancer Inst 88: 1110-1117, 1996.

15. Altaha R, Liang X, Yu JJ and Reed E: Excision repair cross complementing-group 1: Gene expression and platinum resistance. Int J Mol Med 14: 959-970, 2004.

16. Yamada H, Ichikawa W, Uetake H, Shirota Y, Nihei Z, Sugihara K and Hirayama R: Thymidylate synthase gene expression in primary colorectal cancer and metastatic sites. Clin Colorectal Cancer 1: 169-173, 2008.

17. Kuramochi H, Hayashi K, Uchida K, Miyakura S, Shimizu D, Vallbohmer D, Park S, Danenberg KD, Takasaki K and Danenberg PV: 5-fluorouracil-related gene expression levels in primary colorectal cancer and corresponding liver metastasis. Int J Cancer 119: 522-526, 2006.

18. Kobayashi H, Sugihara K, Uetake H, Higuchi T, Yasuno M, Enomoto M, Iida S, Azuma M, Mori R, Omori A, Lenz HJ, Danenberg KD and Danenberg PV: Messenger RNA expression of TS and ERCC1 in colorectal cancer and matched liver metastasis. Int J Oncol 33: 1257-1262, 2008.

19. Sameshima S, Tomozawa S, Kojima M, Koketsu S, Motegi K, Horikoshi H, Okada T, Kon Y and Sawada T: 5-Fluorouracilrelated gene expression in primary sites and hepatic metastases of colorectal carcinomas. Anticancer Res 28: 1477-1481, 2008.

20. Lord RV, Salonga D, Danenberg KD, Peters JH, DeMeester TR, Park JM, Johansson J, Skinner KA, Chandrasoma P, DeMeester SR, Bremner CG, Tsai PI and Danenberg PV: Telomerase reverse transcriptase expression is increased early in the Barrett's metaplasia, dysplasia, adenocarcinoma sequence. J Gastrointest Surg 4: 135-142, 2000.

21. Midgley R and Kerr D: Colorectal cancer. Lancet 353: 391-399, 1999.

22. André T, Boni C, Mounedji-Boudiaf L, Navarro M, Tabernero J, Hickish T, Topham C, Zaninelli M, Clingan P, Bridgewater J, Tabah-Fisch I and de Gramont A: Multicenter International Study of Oxaliplatin/5-Fluorouracil/Leucovorin in the Adjuvant Treatment of Colon Cancer (MOSAIC) Investigators. Oxaliplatin, fluorouracil, and leucovorin as adjuvant treatment for colon cancer. N Engl J Med 350: 2343-2351, 2004.

23. Raymond E, Faivre S, Woynarowski JM and Chaney SG: Oxaliplatin: mechanism of action and antineoplastic activity. Semin Oncol 25: 4-12, 1998

24. Gossage L and Madhusudan S: Current status of excision repair cross complementing-group 1 (ERCC1) in cancer. Cancer Treat Rev 33: 565-577, 2007.
25. Arnould S, Hennebelle I, Canal P, Bugat R and Guichard S: Cellular determinants of oxaliplatin sensitivity in colon cancer cell lines. Eur J Cancer 39: 112-119, 2003.

26. Inokuchi M, Uetake H, Shirota Y, Yamada $H$, Tajima $M$ and Sugihara K: Gene expression of 5-fluorouracil metabolic enzymes in primary colorectal cancer and corresponding liver metastasis. Cancer Chemother Pharmacol 53: 391-396, 2004.

27. Okumura K, Shiomi H, Mekata E, Kaizuka M, Endo Y, Kurumi Y and Tani T: Correlation between chemosensitivity and mRNA expression level of 5-fluorouracil-related metabolic enzymes during liver metastasis of colorectal cancer. Oncol Rep 15: 875-882, 2006.

28. Fujii R, Seshimo A and Kameoka S: Relationships between the expression of thymidylate synthase, dihydropyrimidine dehydrogenase, and orotate phosphoribosyltransferase and cell proliferative activity and 5-fluorouracil sensitivity in colorectal carcinoma. Int J Clin Oncol 8: 72-78, 2003.

29. Kinoshita M, Kodera Y, Hibi K, Nakayama G, Inoue T, Ohashi N, Ito Y, Koike M, Fujiwara M and Nakao A: Gene expression profile of 5-fluorouracil metabolic enzymes in primary colorectal cancer: potential as predictive parameters for response to fluorouracil-based chemotherapy. Anticancer Res 27: 851-856, 2007.

30. Mori K, Hasegawa M, Nishida M, Toma H, Fukuda M, Kubota T, Nagasue N, Yamana H, Hirakawa-YS Chung K, Ikeda T, Takasaki K, Oka M, Kameyama M, Toi M, Fujii H, Kitamura M, Murai M, Sasaki H, Ozono S, Makuuchi H, Shimada Y, Onishi Y, Aoyagi S, Mizutani K, Ogawa M, Nakao A, Kinoshita H, Tono T, Imamoto H, Nakashima Y and Manabe T: Expression levels of thymidine phosphorylase and dihydropyrimidine dehydrogenase in various human tumor tissues. Int J Oncol 17: 33-38, 2000.

31. Uchida K, Danenberg PV, Danenberg KD and Grem JL: Thymidylate synthase, dihydropyrimidine dehydrogenase, ERCC1, and thymidine phosphorylase gene expression in primary and metastatic gastrointestinal adenocarcinoma tissue in patients treated on a phase I trial of oxaliplatin and capecitabine. BMC Cancer 8: 386, 2008.

32. Collie-Duguid ES, Johnston SJ, Boyce L, Smith N, Cowieson A, Cassidy J, Murray GI and McLeod HL: Thymidine phosphorylase and dihydropyrimidine dehydrogenase protein expression in colorectal cancer. Int J Cancer 94: 297-301, 2001.

33. Adam R, Delvart V, Pascal G, Valeanu A, Castaing D, Azoulay D, Giacchetti S, Paule B, Kunstlinger F, Ghémard O, Levi F and Bismuth H: Rescue surgery for unresectable colorectal liver metastases downstaged by chemotherapy: a model to predict long-term survival. Ann Surg 240: 644-657, 2004

34. Folprecht G, Grothey A, Alberts S, Raab HR and Köhne CH: Neoadjuvant treatment of unresectable colorectal liver metastases: correlation between tumour response and resection rates. Ann Oncol 16: 1311-1319, 2005.

35. Kabbinavar FF, Hambleton J, Mass RD, Hurwitz HI, Bergsland E and Sarkar S: Combined analysis of efficacy: the addition of bevacizumab to fluorouracil/leucovorin improves survival for patients with metastatic colorectal cancer. J Clin Oncol 23: 3706-3712, 2005 .

36. Saltz LB, Meropol NJ, Loehrer PJ Sr, Needle MN, Kopit J and Mayer RJ: Phase II trial of cetuximab in patients with refractory colorectal cancer that expresses the epidermal growth factor receptor. J Clin Oncol 22: 1201-1208, 2004. 